\title{
Correlations of recognition memory performance with expression and methylation of brain-derived neurotrophic factor in rats
}

\author{
Pablo C Muñoz ${ }^{1,2,3}$, Mauricio A Aspé ${ }^{1,4}$, Luis S Contreras ${ }^{1,4}$, and Adrián G Palacios ${ }^{1}$ \\ Centro Interdisciplinario de Neurociencia de Valparaíso (CINV), Facultad de Ciencias' ${ }^{1}$ Centro de Estudios en Alimentos Saludables (CREAS) ${ }^{2}$, \\ Universidad de Valparaíso. \\ 3 Pablo Muñoz, Av. Gran Bretaña 1111, Playa Ancha, Valparaíso, Chile; phone: (56-32-2508186), e-mail: pmunoz@cnv.cl \\ 4 These authors equally contributed to this work.
}

\begin{abstract}
Object recognition memory allows discrimination between novel and familiar objects.

This kind of memory consists of two components: recollection, which depends on the hippocampus, and familiarity, which depends on the perirhinal cortex (Pcx). The importance of brain-derived neurotrophic factor (BDNF) for recognition memory has already been recognized. Recent evidence suggests that DNA methylation regulates the expression of BDNF and memory. Behavioral and molecular approaches were used to understand the potential contribution of DNA methylation to recognition memory. To that end, rats were tested for their ability to distinguish novel from familiar objects by using a spontaneous object recognition task. Furthermore, the level of DNA methylation was estimated after trials with a methyl-sensitive PCR. We found a significant correlation between performance on the novel object task and the expression of BDNF, negatively in hippocampal slices and positively in perirhinal cortical slices. By contrast, methylation of DNA in CpG island 1 in the promoter of exon 1 in BDNF only correlated in hippocampal slices, but not in the Pxc cortical slices from trained animals. These results suggest that DNA methylation may be involved in the regulation of the BDNF gene during recognition memory, at least in the hippocampus.
\end{abstract}

Key terms: DNA methylation, recognition memory, synaptic plasticity, hippocampal, perirhinal cortex, BDNF.

\section{INTRODUCTION}

Recognition memory (RM) corresponds to the ability to remember an object that has been previously presented (O'Neil et al., 2009), and depends on the perirhinal, parahippocampal / postrhinal and entorhinal cortices (Lavenex et al., 2002).

Object recognition memory allows discrimination between novel and familiar objects and considers at least two processes: recollection and familiarity (Squire et al., 2007). Recollection involves the successful retrieval of the contextual details that accompanied the learning episode; familiarity involves simply knowing that an item was presented.

It is still not clear which temporal lobe structures are directly involved in both recollection and familiarity, however, it has been proposed that recollection depends on the hippocampus (Wais et al., 2009), whereas familiarity depends on the adjacent Pcx (Haskins et al., 2008).

On the other hand, the importance of brainderived neurotrophic factor (BDNF) for synaptic plasticity and recognition memory has already been recognized (Furini et al., 2009; Heldt et al., 2007; Hennigan et al., 2009). Indeed, it has been shown that lentivirus-Cre-infected animals, with BDNF deletions in the dorsal hippocampus, exhibit an impaired ability to recognize, suggesting that BDNF expression in adult hippocampus is involved in the encoding or consolidation of some component of object recognition memory (Heldt et al., 2007).

Recent evidence suggests that epigenetic mechanisms, such as modification of DNA in the form of DNA (cytosine-5) methylation, play a critical role in the activity-dependent regulation of BDNF (Ma et al., 2009) and other genes (Kangaspeska et al., 2008; Metivier et al., 2008).

Previous studies have shown decreases in methylation of BDNF3 (rat) and BDNF4 (mouse) promoters in response to depolarization (Chen et al., 2003; Martinowich et al., 2003). Moreover, it has been found that inhibitors of DNA methylation block both hippocampal long-term potentiation in electro-physiologic studies in vitro (Levenson et al., 2006) and contextual fear conditioning in behavioral 
studies in vivo (Miller and Sweatt, 2007), suggesting that DNA methylation could be an important molecular mechanism to regulate synaptic plasticity and memory in adult animals.

The aim of this study was to correlate DNA methylation status and recognition memory performance in different temporal lobe structures.

\section{MATERIALS AND METHODS}

Subjects: Thirty-five male rats of the Sprague Dawley strain, 20 and 30 days old, were obtained from the animal facility of the Universidad de Valparaíso. Twenty-four of them were used for preliminary behavioral studies, eight for combined behavioral and molecular biology studies and three for pharmacologic stimulation studies (Table 1). All experiments were performed in accordance with the American Psychological Society standards for the treatment and care of animals. They were housed in groups of four animals in standard conditions of temperature and with a 12-h light/dark cycle, having food and water ad-libitum. The behavioral tasks were made during the dark cycle for the rats.

Apparatus: The apparatus consisted of a polyethylene open field black box $(65 \times 50 \times 50 \mathrm{~cm})$. Behavioral sessions were recorded by a video camera located at $120 \mathrm{~cm}$ above the open field arena. Animal performance was recorded on video and saved on DVD in a computer for later frame-by-frame analysis. A set of three-dimensional similar-sized objects was selected, the objects being made of different materials (plastic, metal, glass) and having different shapes. The objects were heavy enough to be displaced by the rats and each had three identical copies. An ETOH $70 \%$ solution was used to clean the open field arena and objects prior to their introduction to each animal, thus neutralizing olfactory cues.

Spontaneous Object Recognition (SOR) Task: Briefly, before the experimental task each animal was habituated to the open field arena with three consecutive 15 min daily sessions. During the test, animals were exposed to a single session where a sample exploration phase was separated from a choice phase by a delay ( 1 minute, 3 hours and 24 hours for group 1, group 2 and group 3, respectively) (Albasser et al., 2009; Stefanko et al., 2009). In the sample phase, two copies of an object (A1 and A2) were presented for 3 minutes for free exploration. After the sample phase, the animal was removed and placed in a closed box for 1 minute. The open field was then cleaned and the animal was placed in the arena again and presented with two objects, as with the sample phase: one object (A3) was a third copy of one of the previous objects and the other a novel object (B1). Exploratory behavior was defined as direct contact with the nose or front extremities toward the object at a distance less than $2 \mathrm{~cm}$. For the SOR task, the index of discrimination (D1) is defined as the time spent exploring the novel object (B1) minus the time spent exploring the familiar object (A3) (Albasser et al., 2009; Willig et al., 1987). The delay between the sample and choice phases are selected to discriminate when Spontaneous Object Recognition is potentially affected. It is likely that the delay between the sample and choice phases will affect discrimination between familiar and novel objects. Using the above training protocol, we also expected to test the retention times, 1 minute for short-term memory, $3 \mathrm{~h}$ for long-term memory and $24 \mathrm{~h}$ for consolidation.

Hippocampus and perirhinal cortex isolation: Two hours after the trial, the animals were deeply anesthetised with Halotane before decapitation. The brains were removed and immersed in oxygenated (95\% O2, 5\% CO2) ice-cold dissecting saline solution (212,7 mM sucrose, $3 \mathrm{mM} \mathrm{KCl,} 1.25$ mM NaH2PO4, $26 \mathrm{mM} \mathrm{NaHCO} 3,10 \mathrm{mM}$ dextrose, $0.5 \mathrm{mM} \mathrm{CaCl2}$, $10 \mathrm{mM} \mathrm{MgCl2}$ ) and both the hippocampus and Pcx were dissected from bregma, according to the atlas

Table 1

Experimental Groups

\begin{tabular}{|c|c|c|c|c|c|c|c|c|}
\hline & $\mathrm{n}=\mathbf{3 5}$ & Type of study & $\begin{array}{l}\text { Delay } \\
\text { SOR }\end{array}$ & $\begin{array}{c}\text { SOR } \\
\text { Sessions }\end{array}$ & $\begin{array}{c}\text { Western } \\
\text { Blot }\end{array}$ & & MSP & \\
\hline & & & & & Hipoccampus & $\begin{array}{l}\text { Perirhinal } \\
\text { cortex }\end{array}$ & Hipoccampus & $\begin{array}{l}\text { Perirhinal } \\
\text { cortex }\end{array}$ \\
\hline Group 1 & 8 & Behavioral & $1 \mathrm{~min}$ & 1 & - & - & - & - \\
\hline Group 2 & 8 & Behavioral & $3 \mathrm{~h}$ & 1 & - & - & - & - \\
\hline Group 3 & 8 & Behavioral & $24 h$ & 1 & - & - & - & - \\
\hline Group 2 & 8 & $\begin{array}{l}\text { Molecular/ } \\
\text { Behavioral }\end{array}$ & $3 \mathrm{~h}$ & 1 & 8 & 7 & 8 & 8 \\
\hline Group 3 & 3 & Pharmacologic & - & - & - & - & 3 & - \\
\hline
\end{tabular}


of Paxinos and Watson (1997), and immediately stored at $-80{ }^{\circ} \mathrm{C}$.

Western blot analysis: Protein extracts were prepared as described in (Kemmerling et al., 2007). Proteins were resolved in $10 \%$ Laemmli SDS-polyacrylamide gels, transferred to PDVF membranes (Millipore Corp.), and incubated overnight with primary antibody against BDNF, 1:500 (N-20, Sta Cruz Biotech.). To correct for loading, membranes were stripped and re-probed with primary antibody against $\beta$-III-Tubulin, 1:5.000 (G7121, Promega). IMAGE J software processing package (NIH, MD) was used for optical band density quantification.

Pharmacologic Stimulation of Hippocampal Slices: Transverse hippocampal slices ( $n=3$ animals), were incubated in oxygenated ACSF $\left(32^{\circ} \mathrm{C}\right)$ for $1 \mathrm{~h}$ prior to treatment. Slices were treated with either vehicle $(0.001 \% \mathrm{CH} 3 \mathrm{COOH})$ or 5-aza-2-deoxycytidine (30 mM) for 60 minutes immediately after treatment; the hippocampal area was microdissected for DNA methylation assay.

DNA Methylation Assay: DNA was isolated from both hippocampal and Pcx cortical tissue using the Wizard genomic DNA purification kit (Promega, Madison, WI), and processed for bisulfite modification. In bisulphite modification, through a process of deamination, sodium bisulphite converts non-methylated cytosine into uracil, keeping 5-methylcytosine intact. Bisulphite modification was prepared as described by (Clark et al., 1994), modified to the quantities of tissue obtained in the hippocampus and Pcx isolations. Briefly, we i) took $25 \mu \mathrm{L}$ of DNA in TE buffer; ii) denatured the DNA by adding $2,5 \mu \mathrm{l}$ of $\mathrm{NaOH} 3 \mathrm{M}$ and incubating the solution at $42{ }^{\circ} \mathrm{C}$ for 30 minutes; iii) added $255 \mu \mathrm{l}$ of sodium bisulphite (3.9 M, pH 5), $15 \mu$ l hidroquinone $(10 \mathrm{mM}$, to prevent DNA strand breakage during depurization) and $2.5 \mu \mathrm{l}$ of nanopure $\mathrm{H} 2 \mathrm{O}$; and iv) incubated the solution at $55{ }^{\circ} \mathrm{C}$ for $16 \mathrm{hr}$. After this, DNA was purified (Wizard ${ }^{\circledR}$ Clean-Up de Promega) and then eluted in nuclease-free water. The isolated, modified and purified DNA was used as a template for the methylation-specific PCR of the exon I promoter BDNF gene. The primers used to detect methylated DNA in the BDNF-I promoter, at CpG island 1, were: forward: 5' - GTAGCGATT T TGGGGAGGAAGTAC-3', and reverse: $5^{\prime}-\mathrm{CAACCTCTATACG}$ CGACTAAATCCG-3'. The samples were normalized with $\beta$-Tubulin-IV: forward, 5' - G G A G A G T A A T A T G A A T G A T T T G G T - $3^{\prime}$ a n d reve r s , 5'-CATCTCCAACTTTCCCTAACCTACTTAA-3'. PCR was performed using Go-Taq Green Master Mix® (Promega). Each reaction was amplified using the following cycling conditions: $95^{\circ} \mathrm{C}$ for 3 minutes,
40 cycles of $95^{\circ} \mathrm{C}$ for $15 \mathrm{~s}, 58.9^{\circ} \mathrm{C}$ for $1 \mathrm{~min}, 72^{\circ} \mathrm{C}$ for $30 \mathrm{~s}$ and 1 cycle of $72^{\circ} \mathrm{C}$ for 5 minutes, finally maintaining the samples at $16{ }^{\circ} \mathrm{C}$. Finally, amplified products were analyzed by electrophoresis on a $2 \%$ agarose gel stained with ethidium bromide and visualized under UV light (Levenson et al., 2006).

Methylation in Vitro: Methylation in vitro was performed with site-specific SssI (CG) methylase and S-adenosylmethionine (New England Biolabs, Leusden, the Netherlands). Before bisulphite modification, two $\mathrm{mg}$ of isolated DNA was methylated in $50 \mathrm{ml}$ of reaction mixture containing 6 $\mathrm{U}$ of SssI and $640 \mathrm{mmol} / \mathrm{L} \mathrm{S}$-adenosylmethionine at $37^{\circ} \mathrm{C}$ for 60 minutes (Kholod et al., 2007).

Statistical analysis: Statistical analysis was based on ANOVA, and Tukey's post hoc test was used for further comparisons among groups. The behavioral data for the D1 index (see methods) were analyzed in separate analyses of variance. Associations between D1 versus BDNF expression and D1 versus DNA ethylation were examined using Pearson correlations.

\section{RESULTS}

The goal of this study was to examine the role of DNA methylation in recognition memory and to determine which temporal lobe structures could be involved in this type of memory. Rats were tested for their ability to distinguish novel from familiar objects using a SOR task.

First, the rats explored two similar objects (Fig. 1, objects A1 and A2) and after a delay, two different objects were presented; one familiar from the sample phase and one novel.

Recognition was assessed from two measurements. The recognition index D1 is the time exploring object B1, minus time exploring object A3. The recognition index D2 is the difference in time spent exploring the novel and familiar objects, divided by the total time spent exploring objects in the test phase, i.e., D1 divided by total exploration (Albasser et al., 2009). Only the results for the D1 scores are presented, as it was found that some rats showed unusually low levels of exploration. A consequence was the generation of extreme D2 scores (both positive and negative). The occasional presence of these very high or very low scores led to increased variance and thus increased the likelihood of null results.

We first examined the effect of different interphase delay intervals on the performance of rats in the SOR test (Table 1). The 3 different groups with group 1 (1min), group 2 (3 hours) and group 3 (24 hours) did not differ in their exploration time for objects A1 and A2 ( $\mathrm{p}_{\text {group } 1}=0.998, \mathrm{p}_{\text {group } 2}=0.903$, $\mathrm{p}_{\text {group } 3}=0.556$; Fig. $1 \mathrm{~B}$ ). However, the one-way 

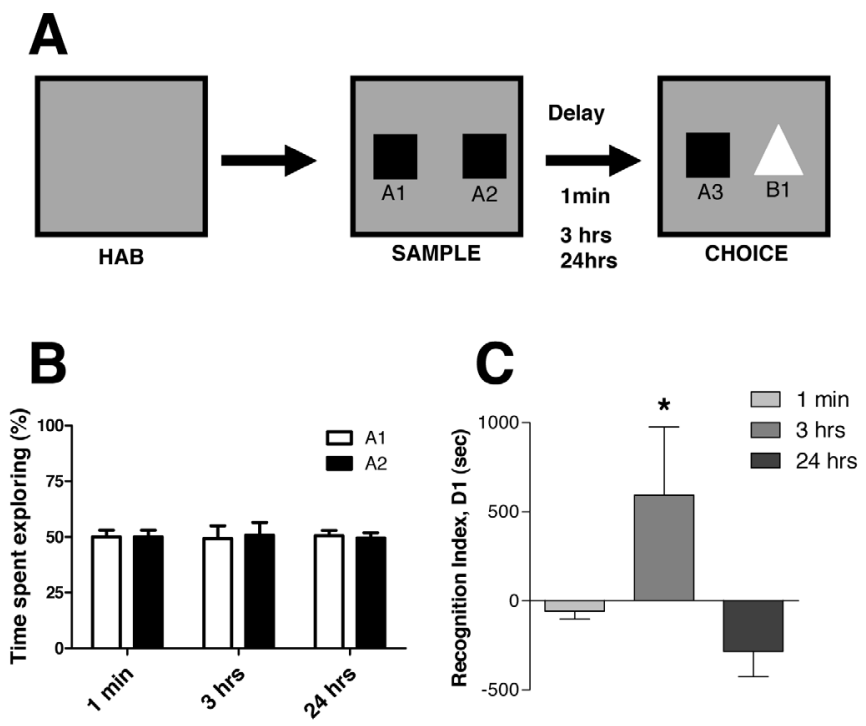

Figure 1: Performance at spontaneous object recognition task: (A) Schematic representation of the task. (B) All groups of rat were habituated and then exposed to the objects $A 1$ and $A 2$ for 3 min. All 3 groups exhibited equal exploration times for each object, in the sample phase. (C) Effect of different inter-phase delay intervals on the performance of rats in the SOR test. Groups of animals received $1 \mathrm{~min}, 3$ hours and 24 hours of delay between phases ( $n=8$, each group). Recognition index (D1) score significantly above 0 indicates recognition of the novel from the familiar object. During the choice phase, animals that received 3 hours of delay displayed a significant preference for the novel object, whereas those that received both $1 \mathrm{~min}$ and 24 hours of delay showed no significant preference. Data are presented as mean $\pm \mathrm{SEM}$. ${ }^{*} \mathrm{P}<0.05$, determined by one-way ANOVA following multiple comparison test.

ANOVA showed a significant effect among groups during choice. Using Tukey's post hoc test $(\mathrm{p}<0.05)$, we found that group 2 had a significantly higher recognition D1 index $(593.0 \pm 382.9, \mathrm{n}=8)$ than group $1(-56.746 .2, \mathrm{n}=8)$ and group $3(-284.7 \pm 141.2$, $\mathrm{n}=8$ ) (Fig. 1 B). Given that group 2 showed better discrimination scores (using a D1 index), rats were exposed to SOR and then subjected to biochemical and biomolecular tests two hours after the trial.

The next step was to determine for group 2 whether expression and DNA methylation of BDNF in the hippocampus and Pcx predicted the degree of D1 recognition memory. We found a negative correlation for group 2 between the immunoreactivity of BDNF and D1 in the hippocampal area (Fig $2 \mathrm{~A}$; $\mathrm{r}=-0.825$, $\mathrm{p}<0.05$ ), but a positive correlation in the Pcx area (Fig $2 \mathrm{~B} ; \mathrm{r}=$ 0.707; $\mathrm{p}<0.05)$.

In order to evaluate DNA methylation in hippocampal and Pcx cortical brain slices from tested subjects, we used a methylsensitive PCR (MSP). The method is based on the bisulfite modification of tested DNA that converts unmethylated cytosine to uracil, whereas methylated cytosine remains unaltered. Subsequently, the modified DNA can be analyzed by MSP using primer specific for the CpG islands located in the promoter region for exon $\mathrm{I}$ of the BDNF gene. To verify the reliability of the method, we incubated rat hippocampus slices with a demethylating and methylation inhibitor agent (5AZA, $30 \mu \mathrm{M})$, obtaining a reduction in the methylation state in BDNF genes compared to nontreated slices (Fig. $3 \mathrm{~A}$ and B). On the other hand, the DNA extracted from non-treated slices was split into two parts. One remained untreated, while the other was methylated in vitro by SssI methylase, resulting in a significant increase compared to untreated DNA (Fig. 3 A and B). This last result suggests that MSP is able to distinguish DNA methylation state variations.

Within the hippocampus, significant positive correlation was found between D1 and DNA methylation of BDNF-1 (Fig 3 C; $r=0.7391$; $\mathrm{p}<$ 0.05 , while in the perirhinal cortex no significant correlation was found (Fig $3 \mathrm{D} ; \mathrm{r}=0.334 ; \mathrm{p}=0.37$ ).

\section{DISCUSSION}

In this study, we addressed the putative role of DNA methylation on gene expression of BDNF and its involvement with the medial temporal lobe structures during recognition memory encoding. During encoding, representations of distinct object 
attributes, such as familiarity vs novelty, are formed in the Pcx and lateral entorhinal area ( $\mathrm{O}^{\prime} \mathrm{Neil}$ et al., 2009). Furthermore, this information is combined with a contextual representation formed in the para hippocampal cortex and medial entorhinal area (Lavenex et al., 2002), helping the specific recovery of items from the perirhinal cortex and lateral entorhinal area (Saunders et al., 2005; Wais et al., 2009). Despite the involvement of hippocampal formation in the neural circuitry supporting recognition memory, shown by lesion studies (Clark et al., 2001; Squire et al., 2007), the role played by the hippocampus remains controversial. Using SOR task, we found a strong correlation between D1 and the expression of BDNF, negative in the
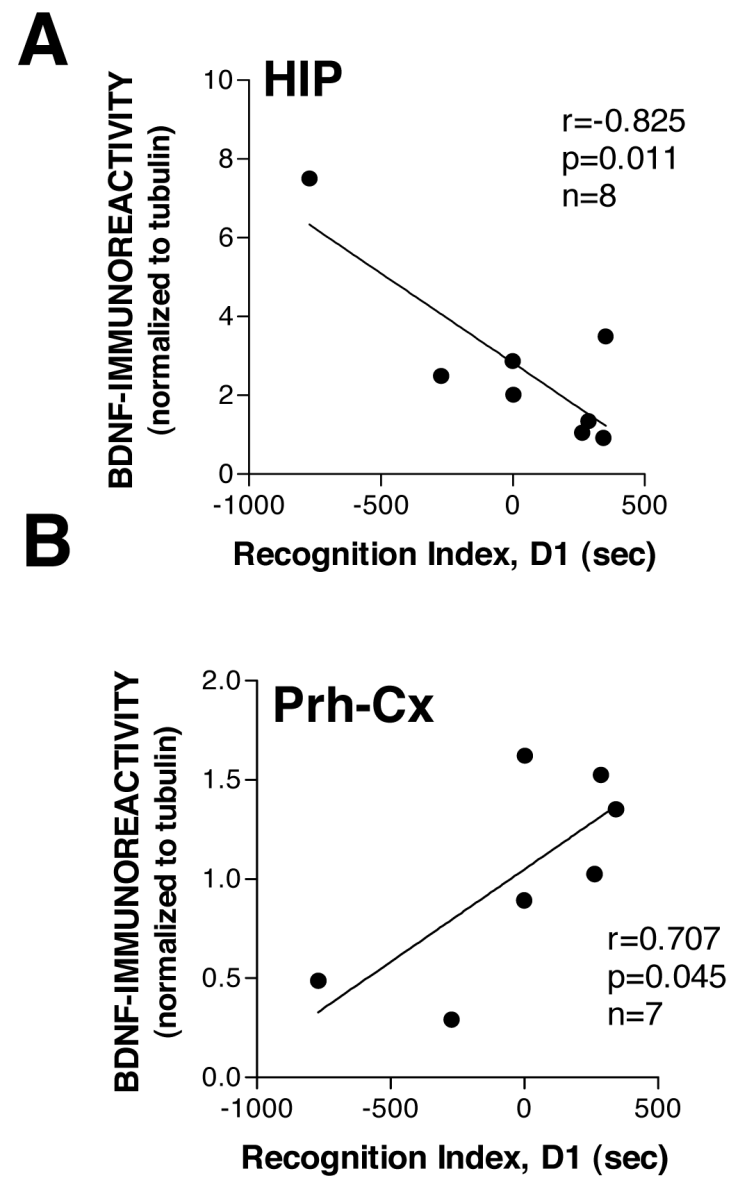

Figure 2. Expression levels of BDNF after object recognition task, in both hippocampal and perirhinal cortex regions: Western blot analysis showed strong correlation between expression levels of BDNF and recognition index (D1), negative in hippocampus (A), but positive in Pcx (B). Data are presented for the D1 scores from the single session. The best-fit slopes correspond to the Pearson correlations (p). Immunoreactivity of BDNF was normalized to tubulin. hippocampus, but positive in the Pcx. This suggests that BDNF could be involved in the mechanism in medial temporal lobe structures that underlies recognition memory. Reduced expression of BDNF in the hippocampus, but increased in cortical structures, suggests that BDNF plays differential roles during coding, providing different aspects associated with the encoding of memory. Indeed, it has been shown that the processing of BDNF is positively correlated with the acquisition, but negatively correlated with extinction, in hippocampal CA1 region (Barnes and Thomas, 2008). Consistently, studies in vitro preparations have shown the differential requirements for mBDNF and proBDNF for hippocampal LTP and LTD, respectively (Pang et al., 2004; Woo et al., 2005).

Consistent with the notion that LTDlike mechanisms may be crucial in recognition memory, studies have demonstrated that LTD in the CA1 region of freely moving rats can be facilitated by novelty acquisition (ManahanVaughan and Braunewell, 1999). In addition, it has been demonstrated that blocking the mechanism of NMDAR-dependent LTD in perirhinal cortical slices prevents visual recognition memory in vivo, (Griffiths et al., 2008).

Although it has been suggested that the primary change underlying perirhinal familiarity is synaptic weakening, as occurs in LTD (Bogacz and Brown, 2003; Brown and Bashir, 2002), an increase in synaptic strength could also be necessary for the neural network to operate efficiently. Our data suggest that a facilitatory mechanism through BDNF, such as is involved in LTP, could be operating in Pcx, in contrast to the hippocampus. The functional role of DNA methylation in regulating the expression of BDNF thus remains an open question.

We were not able to show significant variations in the levels of methylation of the BDNF gene in the hippocampus or Pex (data not shown), but we found a strong positive correlation between the recognition index and DNA methylation of the BDNF in the hippocampus, which is consistent with BDNF gene silencing. Similarly, previous work has shown that methylation levels are correlated to levels of BDNF gene expression (Martinowich et al., 2003).

Contrary to our observations in the hippocampus, we found no correlation between methylation and the recognition index in Pcx, which led to the suggestion that an alternative pathway that does not involve DNA methylation supports the levels of BDNF production, in this area.

Thus, our data indicate that during SOR tasks regulation of gene expression by DNA methylation could be operating in the hippocampus, but not in Pcx. In this regard, it has been shown that within the hippocampus, DNA methylation levels can be 


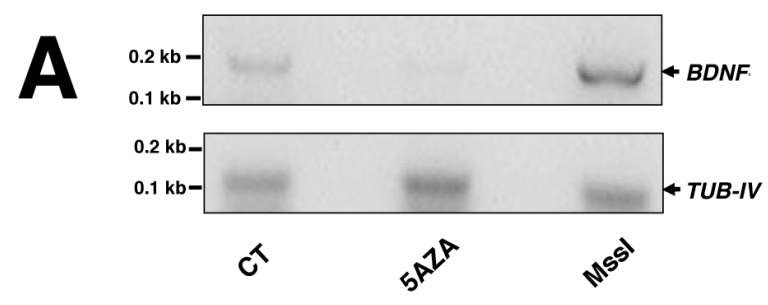

B
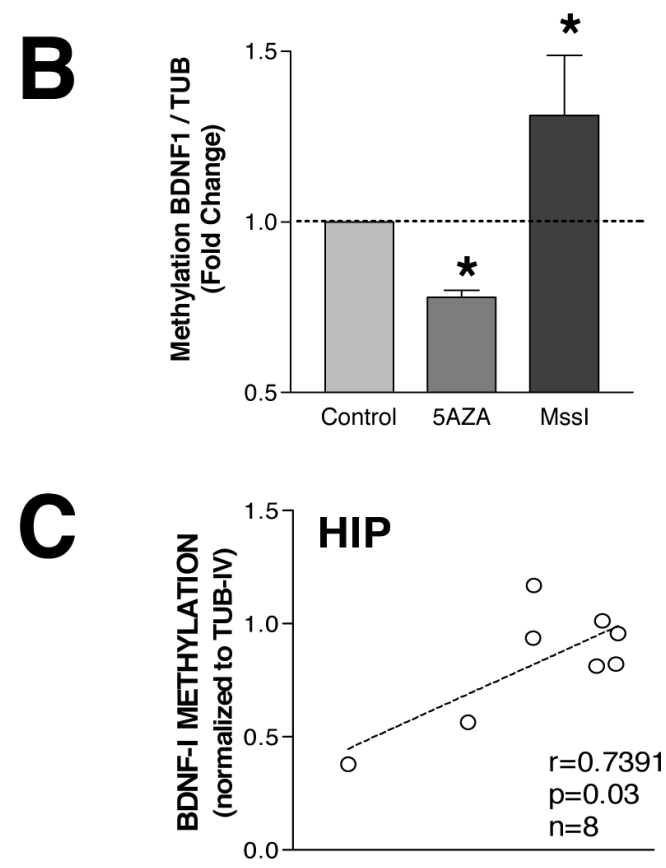

Recognition Index, D1 (sec)
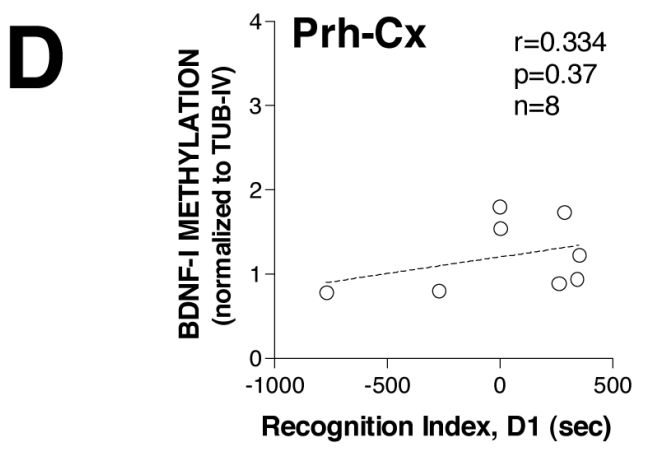

Figure 3. Analysis of BDNF methylation indicates significant correlation with object recognition performance, only in the hippocampal region: (A) Representative agarose gel electrophoresis shows the sensitivity of detection of methylation status. Primer sets as described, were used to amplify the CPG island 1 from exon 1 of BDNF gene (Levenson et al., 2006). Semi-quantitative methylation- specific PCR was used to determine the fold change in methylated DNA in 5AZA treated CA1 slices relative to control treatment. Isolated DNA was methylated in vitro by Sssl methylase and compared with the same untreated DNA preparation. All samples were normalized to tubulinIV. (B) Summary data showing that treatment with 5AZA or Sssl methylase significantly decreased or increased methylated DNA (CPG island1) relative to control samples, respectively. Data are presented as mean $\pm S E M, n=3$, ${ }^{*} \mathrm{P}<0.05$, determined by one-way ANOVA following multiple comparison test. (C) The graph shows that the methylation of BDNF was strongly correlated with the recognition index (D1), in hippocampal area. By contrast, this correlation in the Pcx slices was lost (D). The best-fit slopes correspond to the Pearson correlations ( $P$ ). Immunoreactivity of BDNF was normalized to tubulin. 
rapidly and dynamically altered by environmental stimuli that induce associative learning (Miller and Sweatt, 2007).

In consideration of the presence of high levels of Dnmt3a and Dnmt1 in postmitotic neurons (Feng et al., 2005), we speculate that increased methylation in the hippocampus could be mediated by Dnmt3a or Dnmt1, playing an important role in DNA methylation in the BDNF promoter when neuronal activity is suppressed, as suggested during LTD-like mechanisms in recognition memory (Pang et al., 2004). Whether differential expression patterns of Dnmt3a and Dnmt3b, between both hippocampus and Pcx explain dynamic regulation in DNA methylation levels remains to be seen.

Finally, our data support that object recognition memory involves the hippocampus and Pcx. Moreover, the regulation of BDNF expression, at least in the hippocampus, may be associated with epigenetic mechanisms of DNA methylation.

\section{ACKNOWLEDGEMENTS}

We thank John Ewer for his valuable collaboration in molecular biology experiments. This work was funded by FONDECYT (3080046) and PBCT (ACT 45) grants.

\section{REFERENCES}

ALBASSER, M.M., DAVIES, M., FUTTER, J.E., and AGGLETON, J.P. (2009). Magnitude of the object recognition deficit associated with perirhinal cortex damage in rats: Effects of varying the lesion extent and the duration of the sample period. Behav Neurosci 123, 115-124.

BARNES, P., and THOMAS, K.L. (2008). Proteolysis of proBDNF is a key regulator in the formation of memory. PLoS One 3, e3248.

BOGACZ, R., and BROWN, M.W. (2003). Comparison of computational models of familiarity discrimination in the perirhinal cortex. Hippocampus 13, 494-524.

BROWN, M.W., and BASHIR, Z.I. (2002). Evidence concerning how neurons of the perirhinal cortex may effect familiarity discrimination. Philos Trans R Soc Lond B Biol Sci 357, 1083-1095.

CLARK, R.E., WEST, A.N., ZOLA, S.M., and SQUIRE, L.R. (2001). Rats with lesions of the hippocampus are impaired on the delayed nonmatching-to-sample task. Hippocampus 11, 176-186.

CLARK, S.J., HARRISON, J., PAUL, C.L., and FROMMER, M. (1994). High sensitivity mapping of methylated cytosines. Nucleic Acids Res 22, 2990-2997.

CHEN, W.G., CHANG, Q., LIN, Y., MEISSNER, A., WEST, A.E., GRIFFITH, E.C., JAENISCH, R., and GREENBERG, M.E. (2003). Derepression of BDNF transcription involves calcium-dependent phosphorylation of MeCP2. Science $302,885-889$

FENG, J., CHANG, H., LI, E., and FAN, G. (2005). Dynamic expression of de novo DNA methyltransferases Dnmt3a and Dnmt3b in the central nervous system. J Neurosci Res 79, 734-746.

FURINI, C.R., ROSSATO, J.I., BITENCOURT, L.L., MEDINA, J.H., IZQUIERDO, I., and CAMMAROTA, M. (2009).
beta-Adrenergic receptors link NO/sGC/PKG signaling to BDNF expression during the consolidation of object recognition long-term memory. Hippocampus.

GRIFFITHS, S., SCOTT, H., GLOVER, C., BIENEMANN, A., GHORBEL, M.T., UNEY, J., BROWN, M.W., WARBURTON, E.C., and BASHIR, Z.I. (2008). Expression of long-term depression underlies visual recognition memory. Neuron $58,186-194$.

HASKINS, A.L., YONELINAS, A.P., QUAMME, J.R., and RANGANATH, C. (2008). Perirhinal cortex supports encoding and familiarity-based recognition of novel associations. Neuron 59, 554-560.

HELDT, S.A., STANEK, L., CHHATWAL, J.P., and RESSLER, K.J. (2007). Hippocampus-specific deletion of BDNF in adult mice impairs spatial memory and extinction of aversive memories. Mol Psychiatry 12, 656-670.

HENNIGAN, A., CALLAGHAN, C.K., KEALY, J., ROUINE, J., and KELLY, A.M. (2009). Deficits in LTP and recognition memory in the genetically hypertensive rat are associated with decreased expression of neurotrophic factors and their receptors in the dentate gyrus. Behav Brain Res 197, 371-377.

KANGASPESKA, S., STRIDE, B., METIVIER, R., POLYCARPOU-SCHWARZ, M., IBBERSON, D., CARMOUCHE, R.P., BENES, V., GANNON, F., and REID, G. (2008). Transient cyclical methylation of promoter DNA. Nature 452, 112-115.

KEMMERLING, U., MUNOZ, P., MULLER, M., SANCHEZ, G., AYLWIN, M.L., KLANN, E., CARRASCO, M.A., and HIDALGO, C. (2007). Calcium release by ryanodine receptors mediates hydrogen peroxide-induced activation of ERK and CREB phosphorylation in N2a cells and hippocampal neurons. Cell Calcium 41, 491-502.

KHOLOD, N., BONIVER, J., and DELVENNE, P. (2007). A new dimethyl sulfoxide-based method for gene promoter methylation detection. J Mol Diagn 9, 574-581.

LAVENEX, P., SUZUKI, W.A., and AMARAL, D.G. (2002). Perirhinal and parahippocampal cortices of the macaque monkey: projections to the neocortex. J Comp Neurol 447, 394-420.

LEVENSON, J.M., ROTH, T.L., LUBIN, F.D., MILLER, C.A., HUANG, I.C., DESAI, P., MALONE, L.M., and SWEATT, J.D. (2006). Evidence that DNA (cytosine-5) methyltransferase regulates synaptic plasticity in the hippocampus. J Biol Chem 281, 15763-15773.

MA D.K., JANG, M.H., GUO, J.U., KITABATAKE, Y., CHANG, M.L., POW-ANPONGKUL, N., FLAVELL, R.A., LU B., MING, G.L., and SONG, H. (2009). Neuronal activityinduced Gadd45b promotes epigenetic DNA demethylation and adult neurogenesis. Science 323, 1074-1077.

MANAHAN-VAUGHAN, D., and BRAUNEWELL, K.H. (1999). Novelty acquisition is associated with induction of hippocampal long-term depression. Proc Natl Acad Sci U S A $96,8739-8744$.

MARTINOWICH, K., HATTORI, D., WU H., FOUSE, S., HE, F., HU, Y., FAN, G., and SUN, Y.E. (2003). DNA methylationrelated chromatin remodeling in activity-dependent BDNF gene regulation. Science 302, 890-893.

METIVIER, R., GALLAIS, R., TIFFOCHE, C., LE PERON, C., JURKOWSKA, R.Z., CARMOUCHE, R.P., IBBERSON, D., BARATH, P., DEMAY, F., REID, G., et al. (2008). Cyclical DNA methylation of a transcriptionally active promoter. Nature 452, 45-50.

MILLER, C.A., and SWEATT, J.D. (2007). Covalent modification of DNA regulates memory formation. Neuron 53, 857-869.

ONEIL, E.B., CATE, A.D., and KOHLER, S. (2009). Perirhinal cortex contributes to accuracy in recognition memory and perceptual discriminations. J Neurosci 29, 8329-8334.

PANG, P.T., TENG, H.K., ZAITSEV, E., WOO N.T., SAKATA, K., ZHEN, S., TENG, K.K., YUNG, W.H., HEMPSTEAD, B.L., 
and LU B. (2004). Cleavage of proBDNF by tPA/plasmin is essential for long-term hippocampal plasticity. Science 306, 487-491.

PAXINOS, G., \& WATSON, C. (1997). The rat brain in stereotaxic coordinates (3rd ed.). New York: Academic Press.

SAUNDERS, R.C., MISHKIN, M., and AGGLETON, J.P. (2005). Projections from the entorhinal cortex, perirhinal cortex, presubiculum, and parasubiculum to the medial thalamus in macaque monkeys: identifying different pathways using disconnection techniques. Exp Brain Res 167, 1-16.

SQUIRE, L.R., WIXTED, J.T., and CLARK, R.E. (2007). Recognition memory and the medial temporal lobe: a new perspective. Nat Rev Neurosci 8, 872-883.
STEFANKO, D.P., BARRETT, R.M., LY, A.R., REOLON, G.K., WOOD, M.A. (2009) Modulation of long-term memory for object recognition via HDAC inhibition. Proc Natl Acad Sci U S A. 106(23):9447-52.

WAIS, P.E., SQUIRE, L.R., and WIXTED, J.T. (2010). In Search of Recollection and Familiarity Signals in the Hippocampus. J Cogn Neurosci. 22 (1), 109-123.

WILLIG, F., PALACIOS, A., MONMAUR, P., MHARZI, M., LAURENT, J., DELACOUR, J. 1987. Short-term memory, exploration and locomotor activity in aged rats. Neurobiology of aging 8(5):393-402.

WOO, N.H., TENG, H.K., SIAO, C.J., CHIARUTTINI, C., PANG, P.T., MILNER, T.A., HEMPSTEAD, B.L., and LU, B. (2005). Activation of p75NTR by proBDNF facilitates hippocampal long-term depression. Nat Neurosci 8, 1069-1077. 


\section{Erratum}

In the paper by DANIEL R. SOLIS, EDUARDO G. P. FOX, MÔNICA L. ROSSI and ODAIR C. BUENO entitled "Description of the immatures of Linepithema humile Mayr (Hymenoptera: Formicidae)" published in Biol Res 43: 1, 2010 in page 21, Fig. 1 has been replaced by the following figure:

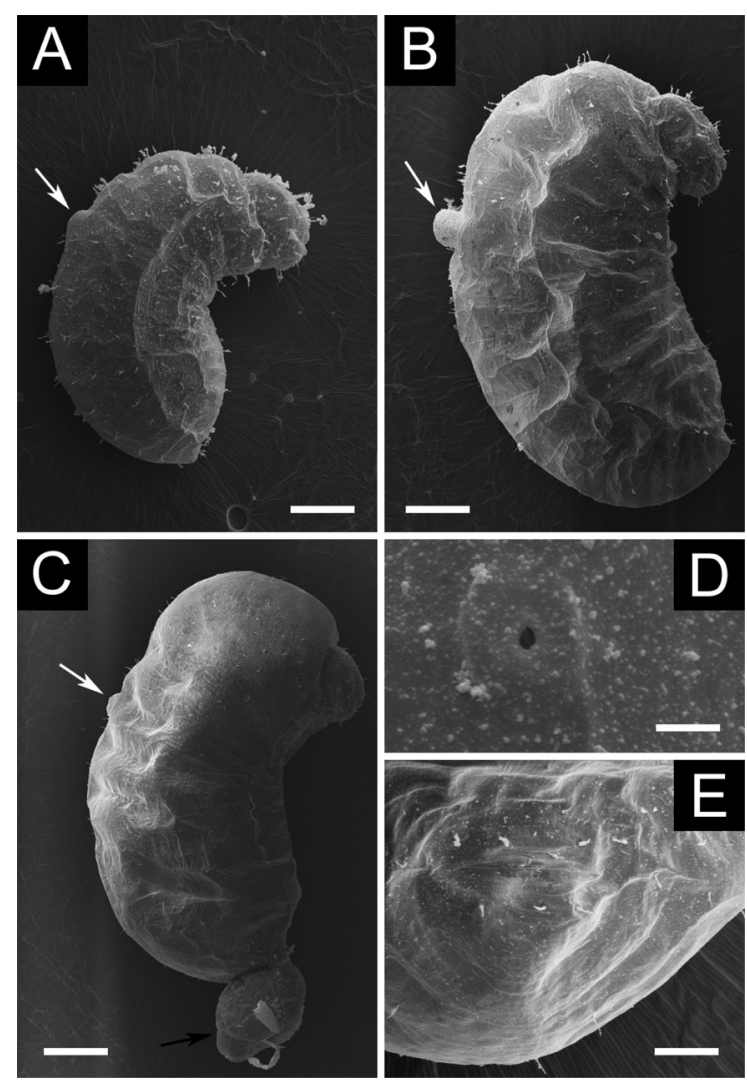

Figure 1: Linepithema humile larvae on side view: (A) First instar larva, (B) Third instar larva, (C) Pre-pupa with meconium (black arrow). White arrows indicate the dorsal protuberance; (D) Spiracle of a first instar larva; (E) Anus and surrounding region of a third instar larva. Scale bars: (A) $0.100 \mathrm{~mm}$; (B) $0.150 \mathrm{~mm}$; (C) $0.225 \mathrm{~mm}$; (D) 0.002 $\mathrm{mm}$; (E) $0.054 \mathrm{~mm}$. 
